\title{
Venalidad, práctica cotidiana y ritual: a propósito de la puja por el empleo de depositario general en el Cabildo de Quito, 1777-1783
}

Miguel Molina Martínez

Universidad de Granada (España) 



\title{
Venalidad, práctica cotidiana y ritual: a propósito de la puja por el empleo de depositario general en el Cabildo de Quito, 1777-1783 ${ }^{1 *}$
}

\section{Venality, daily practice and ritual: Regarding the bid for the job of general depositary in the Cabildo of Quito, 1777-1783}

\author{
Miguel Molina Martínez \\ Universidad de Granada (España) \\ mimolina@ugr.es
}

Fecha de recepción: 29 de noviembre de 2020

Fecha de aceptación: 14 de abril de 2021

\begin{abstract}
Resumen
Este artículo propone una mirada hacia las interconexiones que relacionan la venalidad con el ritual asociado a la misma. La propuesta se acerca al cabildo a través de tres conceptos (venalidad, práctica cotidiana y ritual) con el fin de explorar una faceta de la institución poco transitada. Pretende poner en relación la venta de oficios con los espacios, los símbolos y los ceremoniales que acompañan a su desarrollo. El uso de la costumbre, la plaza pública, los pregones, la toma de posesión o el juramento configuraban un escenario cotidiano en el que el comprador del oficio terminaba convirtiéndose en sujeto activo de la representación del poder local. Se presta especial atención al proceso de la puja por el empleo. Metodológicamente se han utilizado para su análisis expedientes de remate de oficios y actas de confirmación real.
\end{abstract}

Palabras clave: Cabildo de Quito; Depositario general; venta de cargos, Siglo XVIII; Puja; Ritual; Vida cotidiana

$1{ }^{*}$ Esta investigación se realiza en el marco del Proyecto PID2019-104127GB-I00 / AEI / $10.13039 / 501100011033$. 


\begin{abstract}
This article proposes a look at the interconnections that relate venality to the ritual associated with it. The proposal approaches the council through three concepts (venality, daily practice and ritual) in order to explore a facet of the institution with little traffic. It aims to link the sale of trades with the spaces, symbols and ceremonials that accompany its development. The use of custom, the public square, the proclamations, the taking of possession or the oath configured a daily scenario in which the buyer of the trade ended up becoming an active subject of the representation of local power. Particular attention is paid to the job bidding process. Methodologically, records of the auction of trades and actual confirmation records have been used for its analysis.
\end{abstract}

Keywords: Cabildo of Quito; General Treasury; Sale of post; 18th century; Bid to the job bidding process; Ritual; Daily life

\title{
1. INTRODUGGIÓN
}

La investigación sobre los cabildos indianos ofrece en las últimas décadas una inusitada capacidad para profundizar e innovar en el análisis y caracterización del poder municipal. La realidad demuestra que, más allá de planteamientos comunes o generalistas, el estudio de esta institución está abierto a la singularidad local que determina el propio territorio, la situación socioeconómica en la que se desenvuelve. En palabras de García Bernal (2007, p. 257), los cabildos no hicieron sino reflejar la sociedad en la que se encontraban inmersos. Por otro lado, la casuística normativa generada por las propias ordenanzas capitulares, las modificaciones de las leyes generales o los usos arraigados en la tierra contribuyeron a conformar su peculiar personalidad. Como ya advirtieran Zorraquín Becu (1967, p. 314) y Caño Ortigosa (2009), la gran diversidad que se observa entre unos cabildos y otros fue debida, en gran medida, a la falta de un ordenamiento legal que reglamentara su composición y funcionamiento. Por otro lado, las metodologías y formas de abordaje de la institución no son ajenas a los nuevos tiempos, a lecturas distintas y a otras preguntas lo cual redunda en la formulación de nuevos planteamientos y líneas de trabajo. Atrás quedó la época de los enfoques institucionales: Ots (1924, pp. 93-147), Avellá (1934), Altamira (1951), Bayle (1952), Domínguez (1981) o Molina (1996). A ellos siguieron propuestas donde el componente social y el protagonismo de las redes clientelares tomaron carta de naturaleza: Lohmann (1983), Porras (1987), Martínez (1993), González (1994), Ponce (1998), López (1998), Pazos (1999), Santos (1999), García (2000) o Caño (2011). De inmediato, surgió también la necesidad de abordar el fenómeno de la enajenación de cargos y la cuestión de la corrupción en el seno del cabildo con todas las consecuencias que ello implicaba: Tomás y Valiente (1972), Ruiz y Sanz (2007), Andújar (2008), Ponce (2011), Ponce y Andújar (2016). En el presente las propuestas de análisis revelan nuevos y sugerentes caminos por recorrer (Caño, 2019a, pp. 15-37; 2019b, pp. 192-213; 2020). 
Partiendo de la afirmación de Tamar Herzog $(1995$, p. 70) de que la compra de un oficio concejil suponía la puerta de entrada al mundo de los símbolos de autoridad y poder, nuestra aportación propone una mirada hacia las interconexiones que relacionan el hecho mismo de la venalidad con el ritual asociado a la misma. La propuesta se acerca al cabildo a través de tres conceptos (venalidad, práctica cotidiana y ritual) con el fin de explorar una faceta de la institución no demasiado transitada y que pretende poner en relación la venta de los oficios con los espacios, los símbolos y los ceremoniales que acompañan a su desarrollo. La venalidad, en tanto en cuanto mecanismo de acceso al ejercicio del poder, tenía connotaciones simbólicas y rituales que a la postre conducían a su legitimación. El uso de la costumbre, la plaza pública, los pregones, la puja, la toma de posesión y el juramento, entre otros aspectos, configuraban un escenario cotidiano en el que el comprador del oficio terminaba convirtiéndose en sujeto activo de la representación del poder local. La historiografía se ha ocupado en profundidad de los rituales festivos, de la grandiosidad de los festejos político-religiosos desplegados por la América colonial, particularmente en las capitales virreinales, vinculados a la representación del poder (Valenzuela, 2001; Cañeque, 2004; Bridikhina, 2007; Osorio, 2008; Otemberg, 2016). Menor interés ha suscitado la ritualidad inherente a los nuevos espacios y tiempos de índole local (Smietnianski, 2010, pp. 379-408; 2014, pp. 7-32). Para desarrollar esta propuesta hemos centrado la atención en el remate del oficio de depositario general del cabildo de Quito en el siglo XVIII y, particularmente, en el que logró Francisco Javier Arcelus.

\section{EL CABILDO DE QUITO Y LA ENAJENACIÓN DE LA DEPOSI- TARÍA GENERAL}

Las Reales Cédulas de 13 de noviembre de 1581 y 1 de noviembre de 1591 abrieron el camino para la venta y renunciación de oficios concejiles en Indias, especialmente esta última que suprimía los regimientos cadañeros y electivos y ordenó vender los diferentes oficios concejiles (Tomás y Valiente, 1972, p. 92). Únicamente quedaron fuera de esta consideración aquellos oficios considerados jurisdiccionales. Todavía una Real Cédula de 14 de diciembre de 1606 vino a consolidar esta práctica introduciendo la posibilidad de ventas de oficios "por juro de heredad", es decir, a perpetuidad. Estas medidas supusieron en la vida municipal indiana el fin de una etapa y el comienzo de otra (González, 1994, p. 31) y la constitución por primera vez en tierras americanas de "un verdadero sistema de normas sobre ventas y renuncias" (Tomás y Valiente, 1972, p. 138). Mas tarde, otra Real Cédula de Felipe III (Madrid, 3 de junio de 1620) insistía en que en adelante los oficios de regidores en todas las ciudades, villas y lugares de las Indias fueran provistos mediante remate público y no por elección, argumentando eufemísticamente que se hacía "por haberse experimentado los inconvenientes de 
darse por elección"”2. La normativa concerniente a la venta y renunciación de oficios alcanzó con el paso del tiempo un gran desarrollo y requirió de indudables esfuerzos de sistematización (León Pinelo, 1630, II parte). Lo cierto es que el conjunto de tales disposiciones, con claras pretensiones fiscales y recaudatorias, supusieron un cambio drástico en la naturaleza y conformación del poder municipal afectando directamente a las prácticas habituales seguidas en los cabildos con relación al nombramiento de sus componentes. Esta situación tuvo continuidad durante el resto de la centuria y a lo largo del siglo XVIII. El cabildo de la ciudad de Quito no fue ajeno a esta dinámica y en ese tiempo es posible rastrear su incidencia y pormenores. Pilar Ponce dejó constancia de ello para la centuria del Seiscientos, no obstante, que ya desde 1597 comenzaran a venderse las primeras regidurías (Ponce, 1998, pp. 164-190). Ya en el siglo XVIII, entre los años 1723 y 1804, más de 40 expedientes de venta de oficios y confirmaciones reales arrojan bastante luz sobre esta práctica tan generalizada ${ }^{3}$.

La Recopilación de Leyes de Indias dedica los títulos XX, XXI y XXII, del libro VIII a reglamentar de forma precisa todo cuanto concierne a la venta, renunciación y confirmación de los oficios. Allí quedan fijados los argumentos en los que se fundamenta la venalidad, a quienes afecta y los mecanismos de su provisión desde que el oficio sale a remate público hasta la confirmación real. Una rápida lectura de su articulado pone sobre la pista de una serie de actos que implican a diferentes autoridades que van desde el virrey o la Audiencia hasta el propio cabildo. Además, fácilmente son reconocibles espacios como la plaza pública, la sala de Real Acuerdo o el lugar donde se reunían los representantes municipales. Por otro lado, atentos a la literalidad de los documentos, se percibe un hilo discursivo que tiene mucho de ritual ceremonioso y solo entendible desde la solemnidad que se atribuye a la designación de un cargo público. Pese a ello, es difícil presumir una homogeneidad en estos procesos en atención al peso que las circunstancias locales fueron adquiriendo. En cualquier caso, quedó fijado por la doctrina que los oficios renunciables eran aquellos "enajenados por juro de heredad, sobre los cuales el primer comprador y sus sucesores en el oficio tienen a perpetuidad el ius disponendi, si bien éste habrá de ejercerse dentro de las limitaciones legales, concernientes a aspectos de índole formal o al respeto y cumplimiento de plazos preclusivos para la renuncia o su presentación" (Tomás y Valiente, 1972, pp. 126-127).

De entre todos los oficios enajenables en el seno del cabildo, reparamos en el de depositario general. Según las Leyes de Indias, correspondía a este empleo la custodia de todos los bienes muebles e inmuebles embargados y confiscados por los jueces en los procesos judiciales; también la de los de aquellas personas que habían muerto sin

2 Recopilación de Leyes de Indias, lib. VIII, tít. XX, ley VII. "Que los oficios de regidores no se provean por elecciones, ni suertes y se tenga consideración a descubridores y conquistadores".

3 Confirmación real de títulos de regidor de la ciudad de Quito (1723-1804). Archivo General de Indias, Sevilla [en adelante AGI], Quito, 230. 
dejar testamento, siempre con la obligación de devolverlos cuando fuese ordenando. Se excluían los bienes de comunidad de los indios. El escribano del cabildo llevaba un libro de cuenta y razón de los depósitos realizados en coordinación con el propio depositario. Por los demás, la aceptación del oficio comprometía a su titular a dar una fianza en garantía de los bienes que custodiaba y que era revisada anualmente ${ }^{4}$. No obstante, las preeminencias de las que gozaba, las posibilidades evidentes de manejar capital e inversión, además de reconocimiento social e influencia en el ámbito de su jurisdicción le convirtieron en uno de los empleos más atractivos dentro del cabildo.

En Quito la primera venta documentada de una depositaría general data de 1599 (Ponce, 1998, p. 166) y a lo largo del XVII la forma más extendida de acceso a la plaza fue la renuncia de sus titulares. Otro tanto sucedió en la centuria siguiente, aunque algunos lo hicieron a través de un remate en pública subasta. En este periodo se sucedieron cinco titulares: Lorenzo Sáenz de Viteri, José de Olais y Clerque, Francisco Javier de Arcelus, Carlos Pesenti y Mariano Guillermo Valdivieso 5 . La cotización del oficio osciló entre los 5.000 pesos pagados en 1736 a los 15.000 desembolsados en 1777, sufriendo una depreciación a finales de la centuria hasta los 7.000 pesos (Molina, 2015, pp. 198-199). Cantidades nada desdeñables comparadas con las de otras regidurías de la misma ciudad. El cargo de alguacil mayor fue el que tuvo una valoración más parecida al cotizarse sobre los 6.000 y 7.000 pesos entre 1745 y 1799 , con un pico de 8.500 pesos en 1764 . En el caso del fiel ejecutor, su cotización permaneció estable en trono a los 4.000 pesos a lo largo de la centuria. Mención aparte merece el precio pagado por las regidurías sencillas, menos cotizadas, cuyo precio no sobrepasó los 1.300 pesos en la primera mitad del XVIII para descender durante la segunda mitad a una media de 300 pesos (Molina, 2015, pp. 197-200).

Poco se sabe sobre la situación del oficio en las primeras décadas de este siglo. Cuando Sáenz de Viteri pujó por él en 1736 llevaba ya ejerciéndolo una década en calidad de arrendamiento. Fue en ese remate donde lo adquirió en propiedad por los mencionados 5.000 pesos (Ruigómez, 2004-2007, p. 87). Fue aquella una época de graves tensiones dentro del cabildo con numerosos empleos sin cubrir y notorias injerencias del que fuera tesorero de Real Hacienda, Fernando García Aguado. Este logró conformar un grupo de presión con capacidad para intervenir y decidir en la administración local mediante un control de los oficios vendibles y renunciables. Así ocurrió en los remates de 1734 cuando ocho regidurías vacantes fueran provistas

4 Así se establece en Recopilación de Leyes de Indias, lib. IV, tít. X, leyes 15-21.

5 Confirmación real del oficio de depositario general del cabildo de Quito, a favor de Lorenzo Sáenz de Viteri. El Pardo, 12 de febrero de 1739; Confirmación real del oficio de depositario general del cabildo de Quito, a favor de José de Olais y Clerque. Madrid, 7 de mayo de 1762; Confirmación real del oficio de depositario general del cabildo de Quito, a favor de Francisco Javier de Arcelus. Madrid, 12 de julio de 1783; Confirmación real del oficio de depositario general del cabildo de Quito, a favor de Carlos Pesenti. El Pardo, 19 de febrero de 1785; Confirmación real del oficio de depositario general del cabildo de Quito, a favor de Mariano Guillermo Valdivieso. San Lorenzo, 27 de noviembre 1795. AGI, Quito, 230. 
mediante arrendamiento, una modalidad que ofrecía más ventajas para sus intereses (Herzog, 1999, pp. 113-126; Ruigómez, 2004-2007, pp. 78-79; Ramos, 2005, pp. 5377). Las características y prerrogativas de la depositaría general son contempladas de manera particular en los respectivos expedientes de aceptación del oficio por parte de la Audiencia y del virrey, además del título de confirmación real. Esta documentación, además de rasgos generales y comunes del empleo, permite avanzar otras cuestiones que lo singularizan, especialmente si se compara con su equivalente en otras regiones. Del análisis comparativo de estos expedientes es posible extraer similitudes y diferencias que redundan en un mejor conocimiento del cargo. Cuestión nada desdeñable teniendo en cuenta las discrepancias que los investigadores han puesto de relieve acerca de su naturaleza; entre otros aspectos, si se trata de un oficio propio del cabildo o separado de él; instancia a quien compete su provisión; o si se beneficia de un interés por la custodia de los depósitos a su cargo o no, Algunas de estas diferentes visiones fueron apuntadas en Bayle (1952), Avellá (1934), González (1992, pp. 371-401) o Caño (2011, pp. 357-372).

Sobre la primera cuestión, todos los nombramientos de depositario general de la ciudad de Quito en el siglo XVIII que han sido examinados lo son también en calidad de regidor. Es decir, uno y otro van unidos y, en consecuencia, el titular de la depositaría gozaba de asiento y tenía voz y voto en el cabildo. La misma fórmula de regidor y depositario general de manera inseparable se repite en los nombramientos de las ciudades de Guayaquil y Cuenca ${ }^{6}$. Sin embargo, hubo excepciones en las que el oficio fue rematado de forma separada. Tal es el caso de los asientos de Latacunga, Otavalo y Chimbo, tras la solicitud presentada por el mencionado Francisco Javier Arcelus en el sentido de que en dichos lugares se nombraran depositarios generales con independencia del de Quito que él ejercía ${ }^{7}$. Los argumentos esgrimidos merecieron la aprobación y el beneplácito de las autoridades (Molina, 2013, t. II, pp. 367-381). Como cabría esperar, en estos casos la fórmula del nombramiento del nuevo oficio se centraba únicamente en las funciones específicas del depositario general y omitía toda referencia a las competencias propias del regidor ${ }^{8}$. Así pues, conocidos también los casos de las depositarías generales en otros territorios, puede concluirse que a lo largo del siglo XVIII lo habitual fue que este oficio corriera unido al de regidor con todas las prerrogativas que este conllevaba (González, 1992, p. 391; Martínez, 1993, pp. 51-52; Caño, 2011, pp. 362-363). La única vez en la que no se observó fue en el

6 Confirmación real del título de regidor y depositario general de la ciudad de Santiago de Guayaquil, a favor de José de Olave y Gamarra. San Ildefonso, 20 de julio de 1734; Confirmación real del título de regidor y depositario general de la ciudad de Cuenca a favor de José Serrano de Mora. Sevilla, 24 de septiembre de 1732. AGI, Quito, 230.

7 Petición de Francisco Javier Arcelus a José García de León y Pizarro, presidente regente y visitador general de la audiencia de Quito. Quito, 1 de junio de 1781. AGI, Quito, 321.

8 Remate del oficio de depositario general hecho en D. Manuel Galarza. Quito, 25 de mayo de 1784. AGI, Quito, 321. 
caso singular de los corregimientos de Latacunga, Otavalo y Chimbo en los que el oficio de depositario se creó por primera vez.

Por lo que se refiere a la forma de acceso al empleo en el cabildo de Quito, en cuatro ocasiones se recurrió a la subasta pública, si bien una de ellas estuvo precedida por una inicial renuncia. Solamente en un caso durante el siglo XVIII el oficio pasó de un titular a otro mediante la fórmula de la renunciación. Se trata de la renuncia hecha por Carlos Pesenti en Mariano García Valdivieso ${ }^{9}$. De ello se infiere que la depositaría quiteña no fue controlada por ninguna familia; al contrario, quedó expuesta al mejor postor en los remates públicos. La ausencia de un clan o una red clientelar monopolizando el oficio llama la atención a tenor de las prerrogativas y privilegios inherentes al mismo y de las enormes posibilidades de lucro que deparaba. Una realidad que se aleja de la práctica observada en otros cargos del mismo cabildo (Porras, 1987, p. 116).

En cuanto a la facultad del depositario para cobrar un 2,5\% por la custodia de los bienes a su cargo, en Quito no siempre fue así. Aunque la prohibición de ese cobro estaba contemplada en la Recopilación (lib. IV, tít. X, ley XVII), lo cierto es que en la mayoría de los cabildos americanos su titular se beneficiaba de esa prerrogativa (Bayle, 1952, p. 268; Martínez, 1993, p. 52; Caño, 2011, pp. 364365). La práctica observada en la audiencia de Quito así lo confirma también. En un informe de tasación del oficio en 1777 se decía que en tiempos pasados y hasta 1773 los depositarios generales podían "deducir por razón de sus emolumentos el dos y medio por ciento de todo el valor de los fundos depositados", añadiendo que por esta razón "resultaba ser este oficio muy útil y lucrativo"10. Dicha prerrogativa, sin embargo, fue disminuida por determinación de la Real Audiencia en un auto de 4 de mayo de 1773. No por mucho tiempo desde luego, puesto que con motivo del remate celebrado en 1777 su postor volvía a reclamar ese 2,5\% con aprobación del virrey de Santa Fe. Su cobro se siguió practicando por los depositarios posteriores.

\section{PRÁCTICA COTIDIANA Y RITUAL}

La apelación a lo acostumbrado y la observación de un ritual son dos elementos consustanciales en la dinámica de la venta y renunciación de cargos del ámbito local. La norma consuetudinaria, a pesar de que la legislación borbónica no la contemplaba como fuente de Derecho, siguió teniendo plena vigencia y aceptación en la institución del cabildo (Tau, 2001, 143). En este sentido, reiteradamente se dejó al uso de la costumbre la regulación de las prerrogativas que debía gozar el depositario al ser nombrado. Además, la documentación es prolija a la hora de testimoniar el peso jurídico de que gozó la costumbre, el uso y costumbre o lo acostumbrado a lo largo

9 Confirmación real del oficio de depositario general del cabildo de Quito, a favor de Mariano Guillermo Valdivieso. San Lorenzo, 27 de noviembre 1795. AGI, Quito, 230.

10 Tasación de Tomás Bustamante y Ceballos. Quito 11 de abril de 1777. AGI, Quito, 319. 
del remate del oficio hasta su conclusión; lo mismo en la recepción, juramento y asiento en la sala capitular, momentos de gran significado simbólico. Así pues, la coexistencia de la ley y la costumbre determinan todo el proceso y dotan de cierta originalidad cada caso. El ritual, por su parte, implica no solo gestos, sino conductas $\mathrm{y}$ actos que definen una determinada forma de entender y ejercer el poder. La "simbólica del poder" es parte inseparable de los procesos políticos y como tal no debe infravalorarse su análisis a la hora de comprender los mecanismos del poder y su acceso a él (Cañeque, 2004, p. 610). Los símbolos interactúan en un complejo escenario donde autoridad real, prestigio o legitimación desempeñan su particular papel en el momento del ingreso de una persona en la institución del cabildo. Desde que un empleo sale a remate público hasta que es confirmado por el rey sucede un tiempo (que puede alcanzar hasta los cinco años) y concurren una serie de pautas normalizadas, todas ellas rodeadas de una escenografía ritual con significados de diversa índole. En este sentido, el ritual "era para los actores una parte integral de esas actividades que a nosotros se nos presentan como una confusa mezcla de 'política', 'administración', 'gobierno', 'justicia', 'religión', etc.” (Smietniansky, 2010, 402).

Como se apuntó más arriba, el remate público fue la fórmula más utilizada a la hora de proveer la depositaria general del cabildo quiteño a lo largo del siglo XVIII. La práctica cotidiana se concretaba en el anuncio de la vacante, pregones diarios hasta un mes, nueva tasación del oficio, la subasta al mejor postor, el pago del valor de la compra (total o parcial) y de las tasas correspondientes, la adjudicación oficial por las autoridades, la toma de posesión del nuevo titular y juramento en sesión de cabildo y, finalmente, la confirmación real. Cada uno de estos momentos venía rodeado de un ritual específico y simbólico, amparado por las leyes y la costumbre de la región. También los espacios adquirían sentido y contribuían a visualizar la escenografía en la que se representaba la autoridad y el poder: la plaza pública, la Audiencia, la sede del cabildo o la misma Corte.

El caso de la depositaría general comprada por Francisco José Arcelus sirve bien para ilustrar estas ideas al concurrir en él algunos hechos relevantes. Uno, que su provisión comenzara por la vía de la renunciación y concluyera resolviéndose en pública almoneda. Esta circunstancia permite indagar en las diferentes fórmulas al uso en ambas modalidades; otra, que la venta llegara a su fin después de haberse realizado tres remates. El primero fue anulado por incumplimiento de requisitos del único postor y su posterior renuncia. El segundo por la situación deudora con la hacienda real de otro postulante, circunstancia que expresamente prohibían las leyes municipales. En el tercero pujó la persona que no había intervenido en los dos anteriores y terminó obteniendo el empleo, Arcelus. La venta del oficio se resolvió por una cantidad sorprendentemente elevada, la mayor en toda la historia de la depositaría general en la audiencia de Quito y también en otras regiones. Excepcionalmente, se ofrecieron cifras más altas por este empleo, por ejemplo, con ocasión de la venta de la depositaria del cabildo de Puebla en la que Juan de Carmona y Tamariz pagó por ella en 1610 la suma de 30.100 pesos (Illades, 2007, p. 177). 
El proceso que se estudia dio comienzo el 8 de febrero de 1777 cuando José de Olais y Clerque ${ }^{11}$ renunció el empleo de depositario en su hijo mayor, José Olais y Quintana, en calidad de primera opción. Como segunda y tercera opción señaló los nombres de Luis de la Cuesta, alcalde ordinario en aquel momento y del doctor Juan Antonio Domínguez, respectivamente. Sin embargo, la muerte del renunciante cuatro días más tarde, el 12 de febrero ${ }^{12}$, truncó la transmisión del oficio habida cuenta de que el fallecimiento tuvo lugar antes de los 20 días que, según la ley, debían mediar entre la renuncia y la muerte del titular ${ }^{13}$. Por ello y sin más dilación, los oficiales de Real Hacienda, representados en las personas del tesorero Nicolás Ignacio de Jalón y del contador Sebastián Bermúdez Vallador, dispusieron el inmediato remate de la depositaría vacante para que "no se siga perjuicio al Rey y al público" y ordenaron hacer los "30 pregones prevenidos en derecho, en otros tantos días seguidos" en la ciudad de Quito ${ }^{14}$. El mandato iba dirigido al escribano público, quien realizó dichos pregones por voz del indio Vicente Farinango, a la sazón pregonero de la ciudad ${ }^{15}$.

De este modo, el proceso arrancó plenamente legitimado por la autoridad de los oficiales de Real Hacienda, quienes actuaban en nombre del monarca y en salvaguarda de sus intereses económicos. La publicidad del remate a lo largo de un mes sugiere una idea de transparencia y el deseo de que su noticia fuera conocida por el mayor número de vecinos posible. El hecho de que el pregón se hiciera en la plaza pública y a las puertas del palacio de la Real Audiencia abunda en la solemnidad del acto. La textualidad del documento confirma estas circunstancias cuando refiere que el pregón se hace "en altas e inteligibles voces y concurso de mucha gente"16. El escribano público dando fe de cuanto sucedía y con su autoridad avalaba la veracidad y pulcritud del remate que comenzaba.

En el pregón del día 12 de marzo se anunció la novedad de que Ramón Puyol hizo una postura por valor de 4.000 pesos, de los cuales la mitad sería de contado y el resto a pagar en un año. Dado que en los sucesivos pregones no se presentó ningún otro postor, los oficiales reales, con el visto bueno del fiscal de la Audiencia, dieron por

11 José Olais y Clerque venía desempeñando también el oficio de procurador general

12 Carta de Ignacia Quintana, esposa de José de Olais a los oficiales reales. Quito, 28 de febrero de 1777. AGI, Quito, 319.

13 Recopilación de Leyes de Indias, lib. VIII, tít. XXI, ley IV. "Que los renunciantes haya de vivir 20 días y los renunciatarios presenten las renunciaciones dentro de setenta".

14 Auto de los oficiales reales de Real Hacienda. Quito 1 de marzo de 1777. AGI, Quito, 319.

15 La presencia del indio pregonero era una constante, no solo en los remates de oficios concejiles en el distrito de la audiencia de Quito, sino también en el resto de los territorios indianos al estar contemplada por la normativa legal.

16 Testimonio del escribano Juan Narciso Osorio. Quito, 30 de marzo de 1777. AGI, Quito, 319. El contenido del pregón se expresa en los siguientes términos: "Quien quiere comprar y poner en precio del oficio de Depositario general y Regidor perpetuo de este Ilustre Cabildo, que quedó vaco por muerte del capitán don Juan José de Olais y Clerque quien lo obtuvo en propiedad”. El texto termina con la expresión "y no pareció postor alguno" o, en el caso de que lo hubiera, detalla el nombre del que puja y la cantidad que ofrece. 
terminada esta fase y dispusieron la nueva tasación del empleo. Esta era importante por cuanto garantizaba un precio que satisficiera las pretensiones recaudatorias de la Real Hacienda y evitaba que el oficio se vendiese por un valor inferior en el caso de que los postores pujaran a la baja. La tasación era igualmente un mecanismo normalizado conforme a derecho que requería de la aceptación y juramento de los tasadores designados y de un informe razonado de los mismos. Su nombramiento era competencia de los oficiales reales, los ya mencionados Nicolás Ignacio Jalón y Sebastián Bermúdez Valledor. La costumbre había asentado que para este efecto fueran propuestas tres personas, que en esta ocasión fueron el alguacil mayor, Tomás Bustamante; el regidor perpetuo y abogado de la Real Audiencia, Juan Antonio Domínguez y Sebastián Salcedo, quien fuera regidor decano del cabildo a pesar de la oposición que encontró en su ingreso (Ruigómez y Ramos, 2002, pp. 35-61). Todos ellos eran individuos con experiencia en el gobierno local y conocedores de las características de la depositaría general. Más aún, se daba la curiosa coincidencia de que Domínguez había sido la tercera opción como renunciatario de José Olais y Clerque.

El escenario para la aceptación y juramento de los tasadores fue el palacio de la Audiencia ante el fiscal de lo civil, el doctor Joaquín Galdeano y los oficiales reales. Un entorno de referencias simbólicas al monarca y a la religión, según se desprende de la fórmula del juramento realizado. La coletilla final, "así lo juro. Amen”, remata un acto que compromete la imparcialidad del firmante ante Dios y el rey. Los tres nominados aceptaron con su juramento y firma realizar el avalúo del oficio en venta. Sus tasaciones oscilaron entre los 6.500-7.000 pesos de Juan Antonio Domínguez y Tomás Bustamante y los 9.000-10.000 pesos de Sebastián Salcedo. Las diferencias de cálculo respondían al criterio de si la decisión de la Audiencia de restringir el cobro del 2,5\% de los depósitos afectaba o no al valor del empleo. Para los dos primeros, la medida había supuesto una clara depreciación; para Salcedo, por el contrario, la depositaría seguía siendo un oficio muy rentable.

Los oficiales reales, a la vista de estos informes, optaron por la tasación más alta, la que mayor beneficio reportaba al erario real y este fue el criterio que prevaleció por encima de cualquier otro que hubiera podido beneficiar a algún candidato por un avalúo inferior ${ }^{17}$. Mientras tanto, Bartolomé Puyol declaró a los oficiales reales que la puja de su hijo Ramón debía declararse nula, "pues esta la hizo de mi orden hallándose a expensas mías y una vez que este ha tomado el estado de matrimonio a mi disgusto, como es notorio, no se halla hábil para este efecto por las ningunas facultades que tiene". La curiosa forma en que el padre desautorizó a su hijo se inscribe en el marco de las pautas sociales y de prestigio imperantes en aquella época. Como afirma Porras (1987, p. 63), algunas familias podían sentirse injuriadas cuando alguno de sus miembros se casaba con una mujer que no cumpliera la condición de prestigio equiparable, llegando incluso a ser motivo para desheredar. Tal pudo

17 Avalúo de los oficiales reales. Quito, 11 de abril de 1777. AGI, Quito 319. 
ser el caso Bartolomé Puyol, quien al tiempo que renegaba de su hijo se postulaba ofreciendo la cantidad de 5.000 pesos ${ }^{18}$. Esta contrariedad obligó a las autoridades a examinar la licitud de la puja de Ramón Puyol, resultando de ello la suspensión del remate. Después que el fiscal reconociera la impostura de aquel, se señaló un nuevo remate para el día 10 de mayo.

El día anterior Joaquín Arteta presentó ante la Junta de Real Hacienda su propia postura que ascendía a la suma de 7.000 pesos de contado. La puja era claramente inferior a la tasación, pero aun así la formuló en la confianza de que fuera rematada en esa cantidad y los oficiales reales no la anulasen. La propuesta, además, contenía información de interés acerca de lo que el postulante esperaba del empleo. Entre otras cuestiones, pretendía comprarlo

"con todas sus prerrogativas preeminencias, cualidades y, especialmente, la jurisdicción según y como lo han obtenido el dicho don José Olais y sus antecesores, esto es, que comprenda el territorio que se extiende desde el corregimiento de Guaranda inclusive por el de Tacunga, hasta el de Otavalo comprendidos todos los lugares y pueblos de este distrito, y de cada uno de los corregimientos nominados sin excepción alguna, en los cuales me será permitido poner tenientes que en nombre mío administren la Depositaría general, quedando yo a ejercerla personalmente en esta ciudad como cabeza de provincia"19.

La voluntad de dejar patente el ámbito jurisdiccional del oficio delata una de las más importantes prerrogativas de la depositaría general. Cuanta mayor fuera la extensión territorial bajo su jurisdicción, mayor capacidad para beneficiarse de los bienes bajo su custodia y mayores sus ingresos. Sin duda, en la cobertura jurisdiccional radicaba el gran atractivo del oficio y por el que podían arriesgarse elevadas sumas para su compra. El desarrollo de este segundo remate es una prueba evidente de ello. La disputa entre Arteta y Juan Francisco Angulo, un segundo postor, fue inverosímil por la rapidez con que se superaban las pujas. También los oficiales reales debieron asistir sorprendidos ante las sucesivas revalorizaciones hasta el punto de que por dos veces hicieron caso omiso a la solicitud de Arteta de que se investigara a su contrincante por las deudas contraídas con la Real Hacienda ${ }^{20}$. El afán recaudatorio de aquellos era manifiesto y solo cuando el propio Angulo pidió que se aclarase si era persona apta para el empleo accedieron a ello y suspendieron la puja. Todo ello había sucedido el mismo día 10 de mayo y la cantidad ofrecida alcanzaba ya los 15.000 pesos.

El resultado de la pesquisa dio la razón a Angulo en contra de las pretensiones de Arteta. Los argumentos esgrimidos por fiscal arrojan sombras de sospecha sobre su

18 Petición de Bartolomé Puyol. Quito, 9 de abril de 1777. AGI, Quito 319.

19 Petición de Joaquín Arteta a los oficiales reales. Quito, 9 de mayo de 1777. AGI, Quito 319.

20 Escrito de Joaquín Arteta a la Junta de Real Hacienda. Quito, 10 de mayo de 1777. AGI, Quito 319. 
imparcialidad y apuntan cierto trato de favor hacia el primero. Después de reconocer que los deudores no podían obtener empleos de república, sostiene que "en la venta de oficios se debe apetecer la abundancia de postores y que solo deben ser excluidos los que tengan impedimentos verdaderos, ciertos y evidentes en tal grado que no pueda ocultarse por alguna tergiversación". Además, "en el concurso de postores se experimenta el calor de las pujas y de esta resulta el respectivo interés al Erario, como se ha verificado en el caso presente, en el que se ha excedido el valor de este oficio notablemente a su avalúo y al precio en que se remató a Don José Olais". A su juicio, Juan Francisco Angulo "no puede en rigor conceptuarse deudor" y en consecuencia debe declararse "hábil y expedito para la puja y postura de este oficio en cuya declaración se interesa el beneficio de la Real Hacienda" ${ }^{21}$. Podría admitirse que el remate siguiera adelante en busca de un mayor ingreso para las arcas reales, pero no a costa de pasar por alto una deuda que los oficiales reales calcularon en 30.400 pesos. No era la primera vez, sin embargo, que un deudor accedía a un cargo municipal. Una década antes, Juan José de Chiriboga y Luna obtuvo el cargo de alférez real y Joaquín Sánchez de Orellana hacía lo propio como alcalde primero (Porras, 1987, p. 115). La resolución fiscal, afín a los intereses de Angulo, no tuvo el efecto deseado porque la Junta de Real Hacienda desoyó su dictamen y declaró "deudor y por consiguiente inhábil a que se le admita de postor"22.

El tercer remate fue señalado para el día 31 de mayo. En el momento de ser pregonado, esta vez por voz del indio Vicente Calapiña, se dio noticia de la postura de José Olais y Quintana por 12.000 pesos (4.000 de contado y el resto en tres anualidades). Parece que el hijo del anterior propietario quería suceder al padre en el oficio, una vez que se frustró el relevo por la vía de la renunciación. Francisco Javier Arcelus entró en el remate mejorando la postura al ofrecer la misma cantidad íntegra de contado. Si bien la suma ofrecida superaba el precio de tasación, quedaba por debajo de la que habían llegado a pujar Arteta y Angulo con anterioridad. Por ello, el acto fue aplazado hasta el lunes siguiente a la espera de propuestas más elevadas. En la reanudación, Olais no movió su postura y Joaquín Arteta subió progresivamente la puja, replicada siempre por Arcelus hasta la definitiva cantidad de 15.000 pesos que aquel no mejoró. Como práctica asentada por la costumbre, en ese momento el pregonero pronunció las palabras rituales con las que concluía el remate. Significativo era su interés para incitar a mayores pujas:

"Si hay quien quiera hacer mayor y mejor postura parezca, que se le admitirá y se ha de rematar en la persona que más diere. Pues que no hallo quien diga más ni demás, apercibo a remate a la una, a las dos, a la tercera que buena, que buena, que buena pro le haga"23.

21 Dictamen Fiscal. Quito, 19 de mayo de 1777. AGI, Quito 319.

22 Auto de la Junta de Real Hacienda. Quito 27 de mayo de 1777. AGI, Quito 319.

23 Remate del oficio de depositario general de Quito. Quito 2 de junio de 1777. AGI, Quito 319. 
La aceptación del empleo por parte de Arcelus se escenificó en la sala de la Audiencia donde se acostumbraba a celebrar los remates de oficios vendibles y renunciables, en presencia de la Junta de Real Hacienda, tres testigos (Pedro Villamar, Miguel Sandoya y Francisco Saldaña) y "muchas personas más que se hallaban presentes". Como hiciera en su momento Arteta, también Arcelus expuso sus condiciones para desempeñar el empleo y que eran prácticamente similares. La primera, facultad de nombrar tenientes en los corregimientos de Otavalo, Tacunga y Chimbo. La razón no era otra que evitar las dificultades impuestas por la distancia de esos distritos y que por ello no se hiciera ningún deposito. También el nombramiento de un teniente en Quito con voz y voto en su cabildo que le sustituyera en los supuestos de ausencia o enfermedad. La segunda, prohibición de que en los ámbitos de su jurisdicción se hicieran depósitos en cualquier otra persona que no fuera el depositario general o sus tenientes, bajo pena de 500 pesos. La tercera, satisfacción del 2,5\% de todos cuantos bienes estuvieran bajo su custodia, según se había hecho a los antecesores depositarios.

El mismo acto de aceptación implicaba la formalidad de comprometerse con las obligaciones del empleo y garantizar su ejercicio con su persona y bienes muebles y raíces. Asimismo, dar poder cumplido a todas las justicias y jueces y someterse a su fuero y jurisdicción; también renunciar al suyo propio, domicilio y vecindad y la ley sit convenerit de jurisdictione omnium judicum y última pragmática de sucesiones. Se trataba de disposiciones que implicaban la ejecución de lo estipulado sin diferir las obligaciones contraídas y menos ampararse en las leyes que lo pudieran beneficiar Eran cláusulas de renuncia de derechos y reconocimiento de obligaciones introducidas en los juicios civiles ejecutivos muy arraigadas en el Derecho y frecuentes también en los contratos de dotes (Vivas, 2002, vol. II, p. 1824; Tapia, 1829 , T. V, tít. III, cap. I).

Siguió el preceptivo pago en la caja real de los 12.000 pesos de la compra y el abono de las tasas que determinaba la ley (media annata, tercio de emolumentos, derechos de conducción a España y media annatilla). Cumplido este requisito, la Real Audiencia mandó instrucción al cabildo para recibir a Arcelus y tomarle juramento de "usar bien, fiel y legalmente dicho oficio sin agravio de partes" 24 . Tanto el presidente, José Diguja, como los oidores exhibieron su capital simbólico para identificarse frente a los otros oficiales reales y ante los oficios inferiores. Su mandamiento especificaba las funciones y prerrogativas que conllevaba el empleo, coincidiendo con lo ya expuesto más arriba. No obstante, conviene hacer hincapié en aquellos otros aspectos relevantes que aluden al ritual, solemnidad y práctica cotidiana. En primer lugar, sujeción a las leyes "guardando en todo las ordenanzas de estos Reinos", y a la costumbre "usando y ejerciendo dicho oficio según como lo han usado y ejercido los demás sus antecesores". En segundo lugar, reconocimiento de la autoridad y prestigio social del oficio: "y ninguna persona de cualquier estado,

24 Mandamiento de la Real Audiencia. Quito, 12 de junio de 1777. AGI, Quito, 319. 
calidad y condición que sea le ponga estorbo, embarazo, ni impedimento alguno, teniéndolo por tal depositario general y regidor"... le guarden y hagan guardar todas las honras, gracias, mercedes, franquicias, libertades, inmunidades y demás prerrogativas que debe haber y gozar". En tercer lugar, señalamiento de su poder "teniendo voz y voto en dicho cabildo, activa y pasivamente dándosele el asiento correspondiente, según su antigüedad".

Dos meses después y previo pago de una fianza de 8.000 pesos, fue recibido en la sala capitular donde tomó posesión e hizo el juramento "acostumbrado" 25 . Las formas y el ceremonial del acto remitían tanto al derecho consuetudinario, como a las leyes y ordenanzas del rey. El ritual exigía toda la solemnidad ya que se trataba del reconocimiento de una nueva autoridad que pasaba a formar parte del cuerpo concejil. Allí se escenificaba una nueva dimensión de la sacralidad en tanto en cuanto se acataban órdenes emanadas de una autoridad superior y se juraba hacer un buen y fiel uso del oficio (Smietniansky, 2014, 25). Presidía la sesión el corregidor y justicia mayor, José Carrasco, "como era de uso y costumbre", con presencia de todos los regidores "para tratar y conferir cosas tocantes al servicio de Dios Nuestro Señor, de su Católica Majestad y bien de la república"26. La aceptación por parte de los miembros del cabildo era determinante y crucial, ya que de no producirse no podía hacerse efectivo el remate por más que este cumpliera con todos los requisitos legales previos. La capacidad de los regidores para impedir el ingreso de un nuevo individuo está constatada y fue en muchos momentos un mecanismo de control en los difíciles equilibrios de intereses que competían en el seno de la institución.

No obstante haberse producido la incorporación del nuevo empleo en el cabildo, era preceptivo que su titular obtuviera la aprobación y confirmación del virrey de Santa Fe, lo que ocurrió a primeros de diciembre de aquel mismo año. Manuel Antonio Flores estampó su firma "en nombre del Rey y en virtud de sus reales poderes y facultades que de Su Majestad obtengo", tras la verificación de que el remate se desarrolló "con las solemnidades de Derecho"27. Su texto reproduce los extremos ya contemplados en el de la aprobación de la Real Audiencia, aunque la redacción de algunos puntos es más prolija y otros aparecen modificados. Entre estos últimos, el más relevante es la corrección que se hace sobre la calidad del voto. El título expedido por el virrey señala que el oficio sea "con voz y voto en los acuerdos y elecciones activo, pero no pasivo". Es decir, ahora se le privó de su capacidad para ser elegido, en este caso, para alcalde ordinario. No hay mayor explicación acerca de los motivos que indujeron a este cambio. Tampoco se ha hallado ninguna reclamación de Arcelus al respecto. La posterior aprobación y confirmación real nada aclara, ya

25 Recepción de don Francisco Javier Arcelus en el empleo de regidor y depositario general. Quito, 13 de agosto de 1777. AGI, Quito 319.

26 A partir de 1781, tras la supresión del corregimiento, sus atribuciones fueron asumidas por el presidente de la Audiencia quien ganó mayor presencia dentro del cabildo.

27 Título de regidor depositario general a favor de Francisco Javier Arcelus, expedido por el virrey de Santa Fe. Santa Fe, 1 de diciembre de 1777. AGI, Quito, 319. 
que omite cualquier referencia a este aspecto y se reduce únicamente a indicar con la acostumbrada expresión de que ha de tener el oficio "en la propia forma y facultades que vuestros antecesores y se os guarden las honras, preeminencias y privilegios que por este oficio debéis gozar"28. Aunque sin explicitar, debió entenderse que la frase abarcaba todas las condiciones planteadas por Arcelus que, a su vez, reiteraban lo que la tradición ya había asentado. Lo cual implicaba la obtención de unos beneficios que, sin ellos, decía su titular, "no habría quien diese por este empleo 2.000 pesos. Y si lo había comprado por "tan exorbitante cantidad" era justo que "se le guarden todas las franquicias, prerrogativas y privilegios, y se le contribuya con los emolumentos correspondientes al oficio de depositario general, según la práctica y costumbre que se ha observado y se observa con los depositarios de las ciudades de México, Guatemala, Lima y Santa Fe"29.

El título de confirmación real que le expidiera Carlos III el 12 de julio de 1783 es bastante conciso. En su parte expositiva, recoge el hecho de la vacante del anterior depositario y el remate efectuado en Arcelus por 15.000 pesos, el abono de todas las tasas y su aprobación por la Real Audiencia de Quito y por el virrey de Santa Fe. Seguía la aprobación y confirmación del oficio con mandamiento al Cabildo de que lo reciba y le tome juramento (si no lo había hecho ya). Sobre sus funciones y preeminencias remite a lo acostumbrado por los anteriores depositarios; finalmente, le concede poder y facultad para renunciarlo en la forma en que se renuncian "los demás vendibles y renunciables de las Indias, guardando en todo lo dispuesto por leyes y cédulas mías que de ello tratan". Concluye con la disposición de que se tome nota del título en la Contaduría general de Real Hacienda y en la caja de Quito. De los cinco títulos de confirmación real analizados pertenecientes a la ciudad de Quito, salvo el de Sáenz de Viteri (1739) que es más extenso, todos tienen la misma estructura descrita. Por tanto, más allá de poner fecha a la conclusión de un proceso que se remontaba años atrás o que su no existencia causara la vacante del empleo, estos títulos ofrecen una parca información acerca de la singularidad específica del oficio, de sus atribuciones y prerrogativas concretas adaptadas al ámbito local quiteño. Ha sido posible rastrear mejor los rasgos originales de la depositaría general en la documentación expedida por la Junta de Real Hacienda de Quito, la Real Audiencia y el virrey de Santa Fe.

\section{CONGLUSIONES}

El remate de un oficio capitular en pública subasta es el exponente de una política que extendió la venalidad por numerosas instituciones del ámbito peninsular

28 Confirmación real del oficio de depositario general del cabildo de Quito, a favor de Francisco Javier de Arcelus. Madrid, 12 de julio de 1783. AGI, Quito, 230.

29 Solicitud de confirmación real de Bartolomé de la Cámara Martínez, por poder de Francisco Javier Arcelus. Madrid, 9 de septiembre de 1781. AGI, Quito, 319. 
e indiano. Su ejecución estuvo profusamente reglamentada por leyes generales y municipales y fue amparada también por los usos que la tradición había convertido en costumbre con valor igualmente legal. Como todo acto que implicaba el acceso al poder local y su ejercicio por voluntad real, estuvo rodeado del ritual y solemnidad que requería cualquier representación donde la autoridad e imagen de la Corona estuvieran implicadas. El simbolismo de los gestos, los funcionarios implicados o la escenografía elegida contribuían a la legitimación del poder que se compraba, al tiempo que hacían presente a un rey físicamente lejano. El camino por el que transita un particular desde que puja por el empleo hasta su definitiva toma de posesión, simboliza la transformación de un poder económico (capacidad para comprar) en un poder político (jurisdicción real), además de un considerable prestigio social. Un recorrido que lleva de la plaza pública, escenario de los pregones, a la sala capitular, espacio ritual del juramento, entrega de la vara y adjudicación de asiento, cuestión nada trivial. El acercamiento al remate del oficio de depositario general en Quito en sus distintas fases, a los protagonistas, postulantes y representantes reales, y a los espacios en que tienen lugar los hechos ha permitido analizar una faceta del cabildo no tan conocida: la dimensión ritual del poder. Al mismo tiempo, ha proporcionado información concreta, en el marco de una dinámica general común, sobre las peculiaridades locales de este empleo. Estas pueden ser proyectadas para un mejor conocimiento de la depositaría general en el conjunto de la institución municipal. Un eslabón más para perfilar a través de un caso concreto la heterogénea y cambiante naturaleza del poder local y su representación que los cabildos indianos exhibieron a lo largo de su historia.

\section{REFERENCIAS}

Altamira, Rafael (1951). Contribuciones a la Historia Municipal de América. México: Instituto Panamericano de Geografía e Historia.

Andújar Castillo, Francisco (2008). Necesidad y venalidad: España e Indias, 17041711. Madrid: Centro de Estudios Políticos y Constitucionales.

Avellá Vives, Joaquín (1934). Los cabildos coloniales. Madrid: Tipografía de Archivos.

Bayle, Constantino (1952). Los cabildos seculares en la América española. Madrid: Sapientia.

Bridikhina, Eugenia (2007). Theatrum mundi. Entramados del poder en Charcas colonial. La Paz: Instituto Francés de Estudios Andinos/Plural Ediciones.

Cañeque, Alejandro (2004). De sillas y almohadones o de la naturaleza ritual del poder en la Nueva España de los siglos XVI y XVII. Revista de Indias, n. LXIV (232), pp. 609-634. DOI: https://doi.org/10.3989/revindias.2004.i232.427

Caño Ortigosa, José Luis (2009). Los cabildos en Indias. Un estudio comparado. Corrientes: Ediciones Moglia. 
Caño Ortigosa, José Luis (2011). Cabildo y círculos de poder en Guanajuato (16561741). Sevilla: Universidad de Sevilla.

Caño Ortigosa, José Luis (2019a). Los cabildos indianos. Estado de la cuestión, fuentes y archivos para un necesario avance historiográfico. Revista Electrónica de Fuentes y Archivos (REFA) [en línea], n. 10, pp. 15-37. Disponible en: https://refa.org.ar/file. php?tipo $=$ Contenido\&id $=230$

Caño Ortigosa, José Luis (2019b). Fuentes judiciales para el estudio de los cabildos indianos. Temas Americanistas [en línea], n. 42, pp. 192-213. Disponible en: https://institucional.us.es/tamericanistas/uploads/TA-42/10_CANO.pdf

Caño Ortigosa, José Luis (2020). Fuentes primarias para el estudio de las rentas de arbitrios y propios de los municipios indianos.Naveg@mérica. Revista electrónica editada por la Asociación Española de Americanistas [en línea], n. 25. DOI: https://doi.org/10.6018/nav.442051

Domínguez Compañy, Francisco (1981). Estudios sobre las instituciones locales hispanoamericanas. Caracas: Academia Nacional de la Historia.

García Bernal, Manuela Cristina (2000) Las elites capitulares indianas y sus mecanismos de poder en el siglo XVII. Anuario de Estudios Americanos, n. LVII-1, pp. 89-110.

García Bernal, Manuela Cristina (2007). El gobierno municipal de Guadalajara (17001725): ¿un poder muy cotizado?. En: Ruiz Rivera, Julián y Sanz Tapia, Ángel (coord.). La venta de cargos y el ejercicio del poder en Indias. León: Universidad de León.

González Muñoz, Victoria (1992). Las depositarías generales de Yucatán: una regiduría con competencias especiales (siglo XVII). En Torres Ramírez, Bibiano (coord.). Los cabildos andaluces y americanos. Su historia y su organización actual. Sevilla: Patronato Provincial Quinto Centenario/Universidad de Santa María de la Rábida, pp. 371-401.

González Muñoz, Victoria (1994). Cabildo y grupos de poder en Yucatán (Siglo XVII). Sevilla: Diputación Provincial.

Herzog, Tamar (1995). La administración como un fenómeno social: la justicia penal de la Ciudad de Quito (1650-1750). Madrid: Centro de Estudios Constitucionales.

Herzog, Tamar (1999). Redes personales y capitales institucionales: la Real Hacienda y el cabildo de Quito a mediados del siglo XVIII. Fronteras de la Historia, vol. 4, pp. 113-126.

Illades Aguiar, Lilián (2007). La voz pública en la venta de cargos en La Puebla de los Ángeles durante el gobierno de los Austrias. En Ruiz Rivera, Julián y Sanz Tapia, Ángel (2007). La venta de cargos y el ejercicio del poder en Indias. León: Universidad de León, pp. 171-180.

León Pinelo, Antonio (1630). Tratado de confirmaciones reales de encomiendas, oficios $i$ casos en que se requieren para las Indias Occidentales. Madrid: Imprenta Juan González. 
Lohmann Villena, Guillermo (1983). Los regidores perpetuos del cabildo de Lima (15351821). Crónica y estudio de un grupo de gestión, Sevilla: Diputación Provincial.

López Beltrán, Clara (1998). Alianzas familiares, elite, género y negocios en La Paz, s. XVII. Lima: Instituto de Estudios Peruanos.

Martínez Ortega, Ana Isabel (1993). Estructura y configuración socioeconómica de los cabildos de Yucatán en el siglo XVIII. Sevilla: Diputación Provincial.

Molina Martínez, Miguel (1996). El municipio en América. Aproximación a su desarrollo histórico. Granada: Centro de Estudios Municipales y de Cooperación Internacional.

Molina Martínez, Miguel (2013). Honor y legitimidad en la venta y renunciación de oficios de menor cuantía. En Cava Mesa, Begoña (coord.). América en la Memoria: Conmemoraciones y reencuentros. Bilbao: Asociación Española de Americanistas/ Universidad de Deusto, pp. T. II, pp. 367-381.

Molina Martínez, Miguel (2015). La venta de oficios en el reino de Quito (1720-1810). Una aproximación a su cotización. En Olivero Guidobono, Sandra y Caño Ortigosa, José Luis (ed.). Temas americanistas: Historia y diversidad cultural. Sevilla: Editorial Universidad de Sevilla/Servicio de Publicaciones de la Diputación de Sevilla, pp. 198-199.

Osorio, Alejandra (2008). Inventing Lima: Baroque Modernity in Peru's South Sea Metropolis. New York: Palgrave MacMillan.

Otemberg, Pablo (2016). Rituales del poder en Lima (1735-1828). De la monarquía a la república. Lima: Pontifica Universidad Católica del Perú.

Ots Cadequí, José María (1924). El municipio hispanoamericano en la época colonial. Anuario de Historia del Derecho Español, n. 1, pp. 93-157.

Pazos Pazos, María Luisa (1999). El ayuntamiento de la ciudad de México en el siglo XVII: continuidad institucional y cambio social. Sevilla: Diputación Provincial.

Ponce Leiva, Pilar (1998). Certezas ante la incertidumbre. Élite y cabildo de Quito en el siglo XVII. Quito: Abya-Yala.

Ponce Leiva, Pilar (2011). La venta de cargos municipales en Quito en el siglo XVII: consecuencias políticas y dinámicas sociales. En Andújar Castillo, Francisco y Felices de la Fuente, María del Mar (ed.). El poder del dinero. Ventas de cargos y honores en el Antiguo Régimen. Madrid: Biblioteca Nueva, pp. 145-165.

Ponce Leiva, Pilar y Andújar Castillo, Francisco (ed.) (2016). Mérito, venalidad y corrupción en España y América, siglos XVII y XVIII, Valencia: Albatros.

Porras P., María Elena (1987). La elite quiteña en el cabildo, 1763-1805. (Tesis de Maestría. Flacso Ecuador. Disponible en: http://hdl.handle.net/10469/566.

Ramos Gómez, Luis (2005). Enfrentamientos entre grupos de poder por el dominio del Cabildo de Quito entre 1735 y 1739. Revista Complutense de Historia de América, vol. 31, pp. 53-77 
Ruigómez Gómez, Carmen (2004-2007). Alianzas y rivalidades en el cabildo de Quito: el remate de regidurías en 1736. Contrastes. Revista de Historia Moderna, n. 13, pp. 77-92.

Ruigómez, Carmen y Ramos Gómez, Luis (2002). La resistencia del Cabildo de Quito a la entrada del regidor Sebastián Salcedo en 1744 y algunas notas sobre su actuación hasta 1775. Revista Complutense de Historia de América, n. 28, pp. 35-61.

Ruiz Rivera, Julián y Sanz Tapia, Ángel (2007). La venta de cargos y el ejercicio del poder en Indias, León: Universidad de León.

Santos Pérez, José Manuel (1999). Élites, poder local y régimen colonial: el cabildo y los regidores de Santiago de Guatemala, 1700-1787. Cádiz: Universidad de Cádiz.

Smietnianski, Silvina (2010). De preeminencias, estilos y costumbres: rituales y poder en los cabildos coloniales. Una aproximación etnográfica al análisis de materiales de archivo. Revista Colombiana de Antropología, 46 (2), pp. 379-408. DOI: https:// doi.org/10.22380/2539472X.1073

Smietnianski, Silvina (2014). Elecciones capitulares y remate de oficios. Un análisis comparativo para abordar el lugar del ritual en la legitimación del poder. Memoria Americana. Cuadernos de Etnohistoria, n. 22 (1), pp. 7-32.

Tapia, Eugenio de (1829). Febrero Novísimo, o librería de jueces, abogados y escribanos. Madrid: Imprenta de Alfonso Mompié.

Tau Anzoátequi, Víctor (2001). El poder de la costumbre. Estudios sobre el Derecho Consuetudinario en América hispana hasta la Emancipación. Buenos Aires: Instituto de Investigaciones de Historia del Derecho.

Tomás y Valiente, Francisco (1972). La venta de oficios en Indias (1492-1606). Madrid: Instituto de Estudios Administrativos.

Valenzuela Márquez, Jaime (2001). Las liturgias del poder. Celebraciones públicas y estrategias persuasivas en Chile colonial (1609-1709). Santiago de Chile: Dirección de Bibliotecas Archivos y Museos, Centro de Investigaciones Diego Barros Arana.

Vivas, Mario Carlos (2002). Los documentos dotales en Córdoba del Tucumán (15731650). En Barrios, Feliciano (coord.). Derecho y Administración Pública en las Indias Hispánicas. Actas del XII Congreso Internacional de Historia del Derecho Indiano, Cuenca: Universidad de Castilla La Mancha.

Zorraquín Becu, Ricardo (1967). La organización política argentina. Buenos Aires: Instituto de Historia del Derecho Ricardo Levene. 
